\title{
Noninvasive measurements of hemodynamic transition directly after birth
}

\author{
Jeroen J. van Vonderen', Arno A.W. Roest ${ }^{2}$, Melissa L. Siew ${ }^{3}$, Nico A. Blom², Jan M. van Lith ${ }^{4}$, Frans J. Walther', Stuart B. Hooper ${ }^{3}$ \\ and Arjan B. te Pas ${ }^{1}$
}

BACKGROUND: Cardiac output depends on stroke volume and heart rate (HR). Only HR is used to monitor hemodynamic transition.

METHODS: In 24 term newborns born via cesarean section, HR and preductal blood pressure (BP) were measured. Also, using echocardiography, left ventricular dimensions and (Doppler derived) left ventricular output (LVO) were examined at 2, 5, and 10 min after birth.

RESULTS: Mean (SD) HR and BP did not change with time (mean HR: 157 (21) bpm at 2 min, 154 (17) bpm at 5 min, and 155 (14) bpm at 10 min; mean BP: 51.2 (15.4) $\mathrm{mm} \mathrm{Hg}$ at $2 \mathrm{~min}$, 50.5 (11.7) $\mathrm{mm} \mathrm{Hg}$ at $5 \mathrm{~min}$, and $49.6(9.5) \mathrm{mm} \mathrm{Hg}$ at $10 \mathrm{~min}$ ). Left ventricular end-diastolic diameter increased from 2 to $5 \mathrm{~min}(14.3$ (1.3) vs. $16.3(1.7) \mathrm{mm} ; P<0.001)$ and stabilized at $10 \mathrm{~min}(16.7(1.4) \mathrm{mm})$. LVO increased between 2 and $5 \mathrm{~min}$ (151 (47) vs. 203 (55) $\mathrm{ml} / \mathrm{kg} / \mathrm{min} ; P<0.001$ ) and stabilized at $10 \mathrm{~min}(201$ (45) $\mathrm{ml} / \mathrm{kg} / \mathrm{min})$. LVO increase was associated with rise in left ventricular stroke volume $(r=0.94 ; P<0.001)$, not with rise in $\mathrm{HR}$ ( $r=0.37$; $P$ value not significant).

CONCLUSION: Left ventricular dimensions and LVO significantly increased the first 5 min after birth and stabilized at 10 min, whereas BP remained stable. LVO and left ventricular dimension increase are presumably due to increasing left ventricular preload resulting from pulmonary blood flow and ductal shunting increase.

$\mathbf{T}$ he transition to extra uterine life at birth represents a major physiological challenge which begins with lung aeration and the onset of air breathing (1). The initiation of breathing and the resulting pulmonary and hemodynamic changes support the successful transition from fetal to postnatal life. The hemodynamic component of the transition includes a rise in heart rate (HR) (2), a decrease in pulmonary vascular resistance (PVR), and an increase in pulmonary blood flow (PBF) in the very first minutes, which are initiated by lung aeration and an increase in systemic vascular resistance caused by cord clamping (1).

Although pulmonary transition has been the focus of recent experimental $(3,4)$ and clinical studies $(5)$, the subsequent hemodynamic changes and factors regulating this phenomenon are not completely understood (5). The hemodynamic transition is essential for adequate gas exchange and oxygenation of vital organs and is supported by an increase in PBF, which replaces the umbilical circulation in providing preload to the left ventricle (6). However, data obtained from newborn infants are sparse, and most knowledge is based on animal studies $(5,7,8)$. Although these animal studies provide important information that informs our general understanding, it is critical to demonstrate that the findings from anesthetized and ventilated animals are consistent with observations in spontaneously breathing infants. Although cardiac output (CO) depends on HR and stroke volume, HR is the only objective parameter described and currently used to evaluate the hemodynamic condition of an infant at birth (9). Limited data are available on changes in left ventricular dimensions and left ventricular output (LVO) within the first $10 \mathrm{~min}$ after birth. Noori et al. described these measurements after birth. However, the time point and range of the first measurement was 3-7 min, and this study was not designed to assess hemodynamic changes during the first $10 \mathrm{~min}$ after birth (10). Although blood pressure (BP) values are used later in life, they are not routinely measured in the delivery room, and little data are available on BP changes in infants directly after birth.

Therefore, the aim of this study was to assess hemodynamic changes directly after birth with repeated measurements in the first 10 min of life with special focus on changes in left ventricular dimensions and LVO using Doppler imaging.

\section{RESULTS}

The parents of 38 infants were approached for participation in this research, 30 of whom consented. Six infants were excluded for logistical reasons (late arrival of the research team in three cases, absence of the echo cardiographer in one case, and technical difficulty with the echocardiographic measurement in two cases). Therefore, 24 infants have been included. Reasons for an elective cesarean sections were as follows: (i) previous cesarean section (16/24), (ii) fetal position (3/24), (iii) maternal preexisting disease (3/24) (spina bifida, cervix pathology, and previous pelvic fracture), and (iv) parent's request (2/24). All mothers received local anesthesia, shortly before the 
procedure. The infants included in this study had a gestational age of (mean (SD)) 38.5 (0.8) weeks, birth weight of 3,541 (458) $\mathrm{g}$ and Apgar scores (median (IQR)) of $9(8-9)$ at $1 \mathrm{~min}$, $9(8-10)$ at $5 \mathrm{~min}$, and $10(9-10)$ at $10 \mathrm{~min}$. All infants started crying before they arrived at the resuscitation table. None of the infants needed stimulation, positioning, suctioning, or any respiratory support (e.g., application of positive end-expiratory pressure, supplemental oxygen, or positive pressure ventilation) during transition. All measurements were commenced in the 24 included patients at (mean (SD)) time after birth of $120(35) \mathrm{s}, 300$ (0) s, and 600 (0) s after birth. All infants underwent delayed cord clamping varying from 30 to $60 \mathrm{~s}$. None of the infants had any structural cardiac anomalies.

\section{HR, Saturation, and BP}

$\mathrm{SpO}_{2}$ increased significantly in the first $10 \mathrm{~min}$ after birth (Table 1). HR and BP did not significantly change in the first 10 min after birth (Table 1).

\section{Left Ventricular Changes After Birth}

Left ventricular end-diastolic diameter (LVedd) significantly increased from $14.3 \pm 1.3 \mathrm{~mm}$ at $2 \mathrm{~min}$ to $16.3 \pm 1.7 \mathrm{~mm}$ at 5 min $(P<0.001)$ after birth and remained stable between 5 and $10 \mathrm{~min}(16.7 \pm 1.4 \mathrm{~mm}(P=0.15))$. Left ventricular endsystolic diameter (LVesd) increased from $9.4 \pm 1.9 \mathrm{~mm}$ at $2 \mathrm{~min}$ to $10.0 \pm 2.7 \mathrm{~mm}$ at $5 \mathrm{~min}$ and $10.4 \pm 2.0 \mathrm{~mm}$ at $10 \mathrm{~min}$, but LVesd was only significantly different between 2 and $10 \mathrm{~min}$ $(P=0.02)$ (Figure 1). Shortening fraction of the left ventricle increased in the first $5 \mathrm{~min}$ (from $29 \pm 5 \%$ to $33 \pm 7 \% ; P<0.001$ ) after birth and increased further between 5 and $10 \mathrm{~min}$, but this difference did not reach statistical significance $(36 \pm 6 \%$; $P=0.12$ ) (Figure 2).

Left ventricular stroke volume (LVSV) increased significantly from $1.0 \pm 0.3 \mathrm{ml} / \mathrm{kg}$ at $2 \mathrm{~min}$ to $1.3 \pm 0.4 \mathrm{ml} / \mathrm{kg}$ at $5 \mathrm{~min}$ $(P<0.001)$ and remained stable at $10 \mathrm{~min}$ after birth with $1.3 \pm 0.3 \mathrm{ml} / \mathrm{kg}(P=0.99)$. LVO increased significantly from $151 \pm 47 \mathrm{ml} / \mathrm{kg} / \mathrm{min}$ at $2 \mathrm{~min}$ to $203 \pm 5 \mathrm{ml} / \mathrm{kg} / \mathrm{min}$ at $5 \mathrm{~min}(P<$ 0.001 ) and remained stable at $10 \mathrm{~min}$ after birth at $201 \pm 45 \mathrm{ml} /$ $\mathrm{kg} / \mathrm{min}$ (Figures 3 and 4). The increase in LVSV was highly correlated with the increase in LVO between 2 and $5 \mathrm{~min}(0.94$ $(P<0.001)), 5$ and $10 \mathrm{~min}(0.92(P<0.001))$, and 2 and $10 \mathrm{~min}$ $(0.90(P<0.001))$. There was a moderate-to-weak correlation

Table 1. Changes of $\mathrm{BP}, \mathrm{HR}$, and $\mathrm{SpO}_{2}$ at 2,5 , and 10 min after birth

\begin{tabular}{lccccc}
\hline $\begin{array}{l}\text { Parameter } \\
\text { (mean (SD)) }\end{array}$ & $2 \mathrm{~min}$ & $5 \mathrm{~min}$ & $10 \mathrm{~min}$ & $\begin{array}{c}P \text { value } \\
2-5 \mathrm{~min}\end{array}$ & $\begin{array}{c}P \text { value } \\
5-10 \mathrm{~min}\end{array}$ \\
\hline $\begin{array}{l}\mathrm{BP} \text { systole, } \\
\mathrm{mm} \mathrm{Hg}\end{array}$ & $68.3(18.3)$ & $71.9(13.2)$ & $70.9(10.5)$ & 0.48 & 0.94 \\
$\begin{array}{l}\mathrm{BP} \text { diastole, } \\
\mathrm{mm} \mathrm{Hg}\end{array}$ & $41.6(16.0)$ & $38.3(11.4)$ & $36.4(12.3)$ & 0.48 & 0.74 \\
$\begin{array}{l}\mathrm{BP} \text { mean, } \\
\mathrm{mm} \mathrm{Hg}\end{array}$ & $51.2(15.4)$ & $50.5(11.7)$ & $49.6(9.5)$ & 0.76 & 0.82 \\
$\mathrm{HR}, \mathrm{bpm}$ & $157(21)$ & $154(17)$ & $155(14)$ & 0.52 & 0.70 \\
$\mathrm{SpO}_{2^{\prime}} \%$ & $70(18)$ & $81(14)$ & $92(6)$ & 0.01 & 0.001 \\
\hline $\mathrm{BP}^{\mathrm{b}}$ & & & & & \\
\hline
\end{tabular}

$\mathrm{BP}$, blood pressure; $\mathrm{HR}$, heart rate. between the increase in HR and LVO, which did not reach significance at all time points ( 2 and $5 \mathrm{~min}(0.37(P=0.09)), 5$ and $10 \min (0.20(P=0.07))$, and 2 and $10 \min (0.40(P=0.37)))$.

\section{DISCUSSION}

Noninvasive cardiac measurements directly after birth demonstrated a rapid increase in LVO within the first minutes after birth, with no change in BP and no further increase in $10 \mathrm{~min}$ after birth. LVO was strongly correlated with the increase in LVSV between 2-, 5-, and 10-min time points. HR only showed a weak correlation with the increase in LVO. As the increase in LVedd was larger than that of LVesd, causing an increase

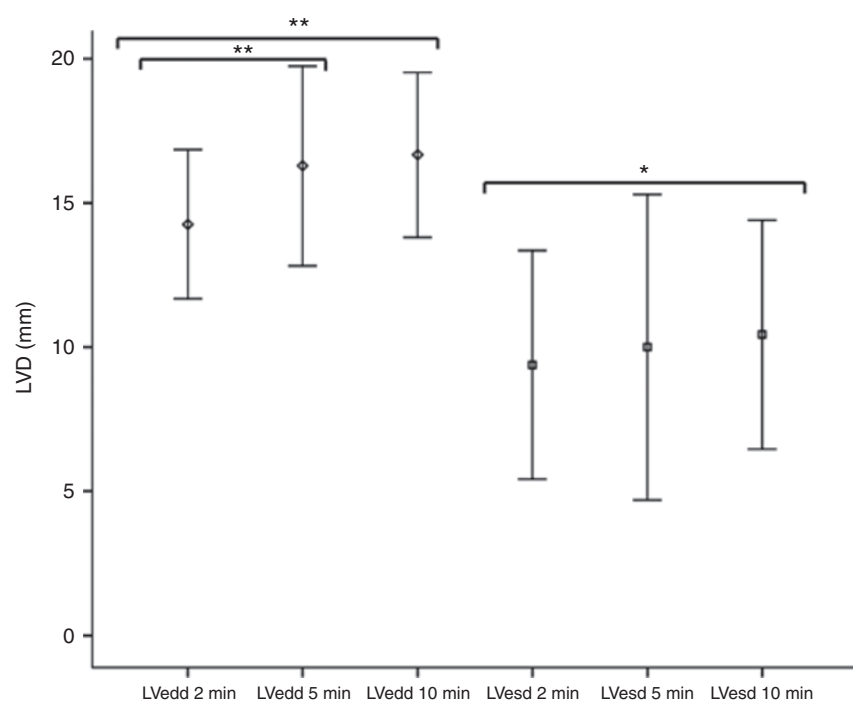

Figure 1. Change of left ventricular dimensions (LVD). Change of left ventricular end-diastolic diameter (LVedd; $\mathrm{mm}$ ) and change of the left ventricular end-systolic diameter (LVesd; $\mathrm{mm}$ ) during 2-, 5-, and 10-min time points after birth. Plots show mean values and 2 SD of data. ${ }^{* *} P<$ $0.001 ;{ }^{*} P<0.01$.

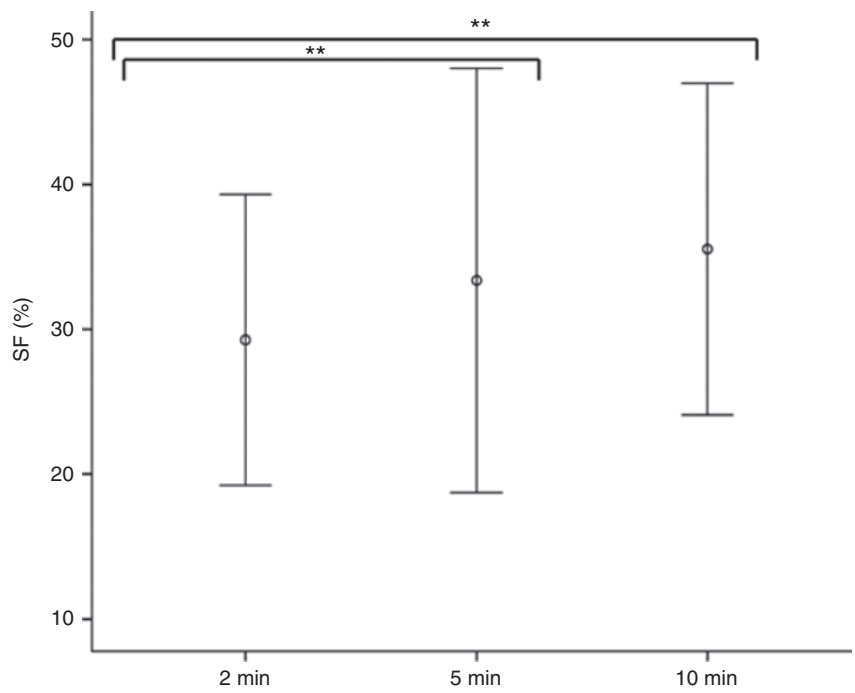

Figure 2. Change in shortening fraction of the left ventricle. Shortening fraction (SF; \%) of the left ventricle during 2-, 5-, and 10-min time points after birth. Plots show mean values and 2 SD of data. ${ }^{* *} P<0.001$. 


\section{Articles $\mid$ van Vonderen et al.}

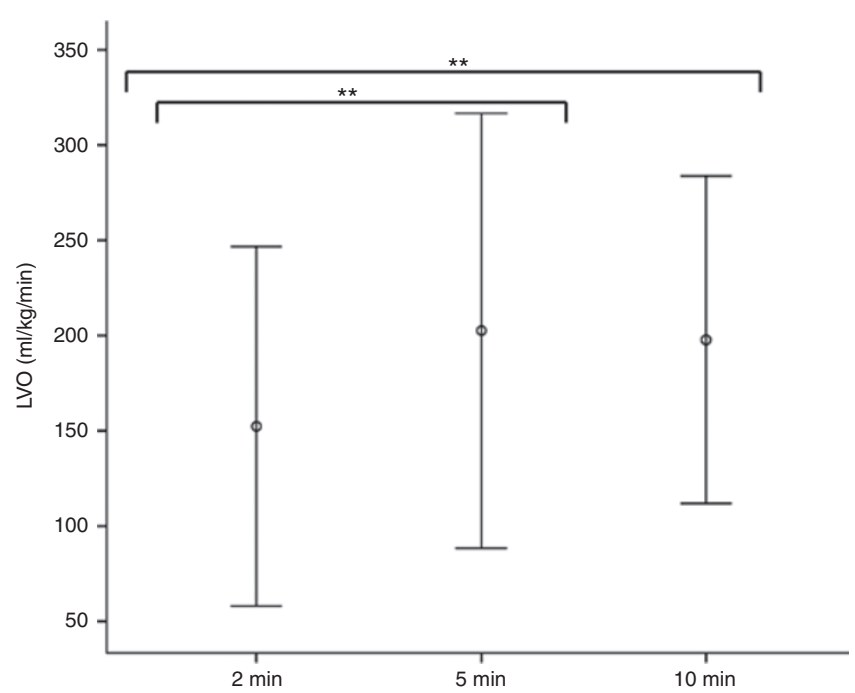

Figure 3. Change of the left ventricular output (LVO). Changes in left ventricular output in $\mathrm{ml} / \mathrm{kg} / \mathrm{min}$ during 2-, 5-, and 10-min time points after birth. Plots show mean values and 2 SD of data. ${ }^{* *} P<0.001$.

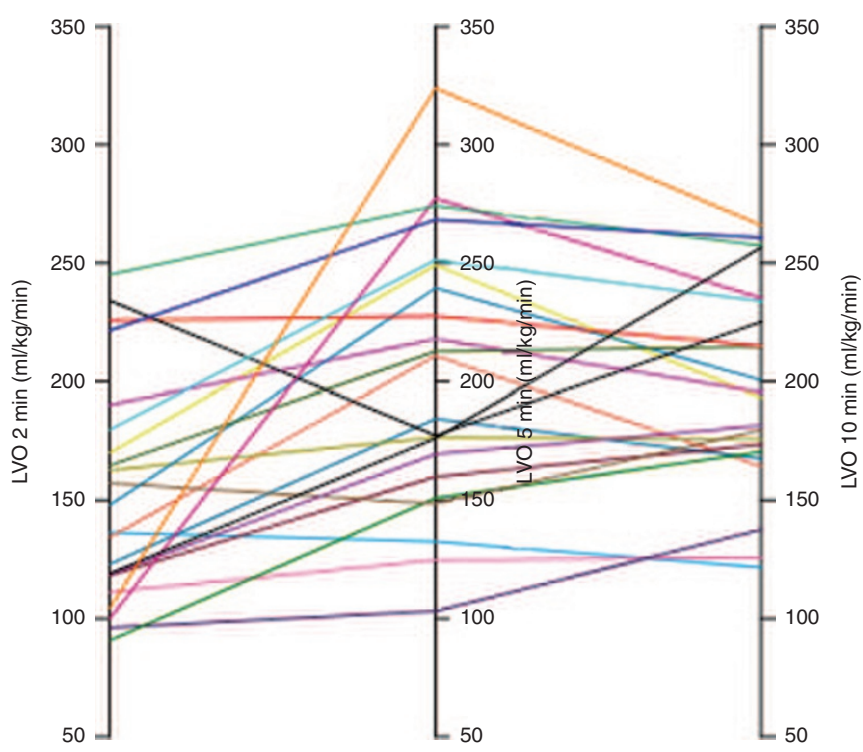

Figure 4. Individual changes of left ventricular output (LVO). Individual changes of left ventricular output $(\mathrm{ml} / \mathrm{kg} / \mathrm{min}$ ) for all patients during 2-, 5-, and 10-min time points after birth.

in shortening fraction, we speculate that increased preload mainly induces the increase in LVSV.

Despite the rapid increase in LVO, preductal BP remained unchanged in the first $10 \mathrm{~min}$ after birth and was comparable to known values measured over the first day after birth (11). $\mathrm{BP}$ is the product of $\mathrm{CO}$ and vascular resistance and is mediated by cardiovascular reflexes, capillary fluid shifts, stress and relaxation, and hormonal control (such as adrenalin) (12). It is possible that the decrease in PVR and increase in systemic vascular resistance following lung aeration and umbilical cord clamping mitigated the increase in $\mathrm{CO}$, resulting in no change in BP. Alternatively, the sudden increase in ductal leftto-right shunting caused by the decrease in PVR and increase in systemic vascular resistance may provide an alternate low resistance pathway for LVO (6). Indeed, experimental and human data showed that the increase in left-to-right shunting through the ductus arteriosus contributes to $~ 50 \%$ of $\mathrm{PBF}$ immediately after birth and ensures that pulmonary venous return and left ventricular preload are increased $(6,10,13)$. Presumably, this explains the increase in LVO that we observed immediately after birth.

After cord clamping, the increase in left ventricular preload and the resulting increase in LVO are dependent on the increase in PBF. In newborn lambs, left ventricular preload was compromised when the cord was clamped in the absence of lung aeration and increase in PBF (6). Lung aeration and increase in PBF before clamping the cord will minimize the compromise to LVO, because PBF can replace the umbilical venous return as the source of preload. As umbilical cord clamping was delayed by $30-60 \mathrm{~s}$ in this study, it is highly likely that all infants had commenced breathing, aerated their lungs, and initiated an increase in PBF before their umbilical cords were clamped. This may explain why we observed only a $25 \%$ increase in LVO, whereas previous animal experiments have reported a $50 \%$ reduction after cord clamping preceding ventilation, followed by a $50 \%$ increase when ventilation was started (6).

In the human fetus, LVO was estimated to be $179 \mathrm{ml} / \mathrm{kg} /$ min, not dependent on gestational age (14). These values are comparable to measurements of LVO in sheep fetuses (15). We observed that LVO increases to $203 \mathrm{ml} / \mathrm{kg} / \mathrm{min}$ in the first $10 \mathrm{~min}$ after birth, which is similar to values reported in other studies at $15 \mathrm{~min}(235 \mathrm{ml} / \mathrm{kg} / \mathrm{min})(16)$ and $20 \mathrm{~min}(190 \mathrm{ml} / \mathrm{kg})$ (10) after birth. The increase in LVO that we and others have observed in humans is less than the increase in LVO that was reported in lambs, which doubled after birth as compared with fetal values possibly due to a higher metabolic demand at this time (15). The higher values of CO observed in animals may also be explained by the difference in species.

Compared with values of LVSV measured in the fetus $24 \mathrm{~h}$ before birth $(1.21 \mathrm{ml} / \mathrm{kg})$, LVSV measured in our study is increased $(2.25 \mathrm{ml} / \mathrm{kg})$ immediately after birth (17) but decreases in the hours thereafter $(16,17)$. Similar changes have been observed in animal studies $(6,15)$. Our results extend these observations by demonstrating that directly after birth, a rapid increase in LVO occurs, mainly due to an increase in LVSV. Although it is widely believed that HR is the primary determinant of $\mathrm{CO}$ in the newborn due to an inability to increase stroke volume (18), our findings clearly indicate that LVO is not only determined by HR but also by changes in LVSV. As HR did not change significantly in our study, this had only moderate influence on the change in LVO.

The changes in LVO and LVSV during neonatal transition begin when the cord is clamped and the infant starts to breathe $(8,18)$. Rising PBF, caused by increased left-to-right ductal shunting and decreased PVR (6), most likely explains the increase of LVedd, which is responsible for the increase in shortening fraction at $5 \mathrm{~min}$ after birth as LVesd was not altered. Besides the increase in left atrial preload, the increase in LVedd might also be influenced by the reduction in pericardial 
pressure and increase in cardiac compliance after the onset of breathing and increase in preload (19). The change in preload can explain the increase in stroke volume by the Frank-Starling mechanism. Similarly, as LVesd is influenced by afterload, it is not surprising that this was only slightly altered in our study as systemic arterial pressure was not increased.

\section{Limitations}

It is possible that our measurements were influenced by a delayed cord clamping. Although delayed cord clamping has beneficial effects on outcome for both preterm and term newborn infants, the exact timing necessary for the most benefit has not been established (20). Delayed cord clamping has shown to be beneficial for vascular filling, superior vena cava blood flow, right ventricular output, and right ventricular stroke volumes at $48 \mathrm{~h}$ (21). The delay of cord clamping could diminish the effect of the significant loss of venous return that accompanies cord clamping (6), causing the reported changes in LVO to be less compared to changes in LVO in infants after immediate clamping.

Ductal flow and the increase in ductal left-to-right shunt after birth are important in the increase in PBF and pulmonary venous return. However, due to time restrictions and our focus on changes in LV dimensions and output, we did not assess changes in ductal flow and right ventricular output at the various time points after birth.

The echocardiographic measurements could have changed the activity level of the infant. However, we did not observe differences in HR and BP throughout the measurement period. HR was similar to median values observed in healthy term infants (2). Echocardiographic measurements were not analyzed blinded, as the timer is shown in the recordings, and all loops for measurements are chronically numbered. This could have led to bias. However, we did not anticipate such large differences found between the 2- and 5-min time points. We report values for a relatively small group. However, the observed changes are highly significant using echocardiographic techniques. Furthermore, Tsai-Goodman et al. and Hudson et al. have shown that echocardiographic measurements of the aortic annulus in neonates were highly reproducible $(22,23)$. Also, the determination of LVO by Doppler-derived measurements has been shown to be a reliable technique to asses changes in LVO within subjects $(23,24)$. Preferably, the measurements would have to be performed during normal transition after vaginal births and not in nondistressed infants born after elective cesarean section. Also, the cesarean section could have influenced the transition. We were not allowed to perform the study in vaginal deliveries as this would have large impact on the standard care. However, most infants underwent cord clamping at 30-60 s after birth, which allows time for the newborn infant to breathe. Results, therefore, may be comparable to vaginally born infants, where delayed cord clamping is utilized.

\section{Conclusion}

The unique data reported in this study provides new insights in the immediate cardiac adaptation directly after birth.
We showed that a normal transition causes a significant rise in LVedd and LVO most likely due to an increase in preload due to decrease in PVR. Throughout the period of early transition, $\mathrm{BP}$ is maintained at the same level.

Our findings in spontaneously breathing infants at birth will add to the current knowledge of what actually happens during transition. A better understanding of the normal physiological adaptation is essential when attempting to understand problems associated with circulation in the immediate newborn period and to develop strategies to support transition.

\section{METHODS}

The Leiden University Medical Center is a tertiary perinatal center. For our study, we included healthy term infants ( $\geq 37 \mathrm{wk}$ of gestation) delivered by elective cesarean section. The study was approved by the Institutional Review Board of the Leiden University Medical Center. Parents were approached during preoperation visit or by telephone at least $1 \mathrm{~d}$ before the cesarean section.

Because the cesarean sections were scheduled, we were able to prepare our equipment in due time. Only infants with an uncomplicated transition at birth (e.g., no respiratory support necessary) were included. None of the women were in labor during the time of the elective cesarean section. There, the infants were not distressed during birth. All infants with suspected malformations or infants who required any form of respiratory support (application of positive endexpiratory pressure, extra oxygen, or positive pressure ventilation) during transition were excluded.

A stopwatch was started as soon as the infant was born (i.e., when the shoulders were delivered). In accordance with local guidelines, the umbilical cord was clamped 30-60 s after birth and cut by the obstetrician. Therefore, most infants would have commenced breathing before cord clamping. Thereafter, the baby was placed under a radiant heater, and the neonatal caregiver, who was not involved in the research project, provided standard care (drying, keep warm, and evaluation of the infant's condition). Stimulation, positioning, and suctioning only took place when needed. All measurements were collected at three time points after birth: as soon as the infant was placed on the resuscitation table and at 5 and $10 \mathrm{~min}$ after birth. During this period, the infant remained on the resuscitation table.

$\mathrm{SpO}_{2}$ was measured continuously using a Masimo Radical 7 pulse oximeter (Masimo, Irvine, CA) with a LCNS Neo-3 sensor (Masimo) placed around the ulnar aspect of the infant's right wrist. Electrocardiogram electrodes were fixed as soon as the infant reached the resuscitation table, and HR was determined using an electrocardiogram that was recorded during and in synchrony with the echocardiographic examination (25).

Noninvasive BP was measured preductally using an IntelliVue MP30 Philips Monitor (Philips, Eindhoven, the Netherlands) with a neonatal cuff size 4 (Philips) placed on the right upper arm. During a preliminary study, we found that simultaneous measurements of $\mathrm{BP}$ and $\mathrm{SpO}_{2}$ led to a low signal on the Masimo pulse oximeter, even if the maximal sensitivity mode is used. Therefore, BP measurements were limited to a very short period, and $\mathrm{SpO}_{2}$ values were measured immediately after the cuff was released.

To assess the immediate changes in cardiac function after birth, an echocardiographic examination was performed using a Vivid I Cardiovascular Ultrasound system equipped with a $7.0 \mathrm{MHz}$ transducer (GE Healthcare, Waukesha, WI). Furthermore, electrocardiogram leads (Neotrode II; Conmed, Utica, NY) were placed. Echocardiographic measurements were obtained as soon as the infant was placed on the resuscitation table and at 5 and 10 min after birth. Standard two-dimensional gray scale images were acquired from the parasternal and apical views, including M-mode assessment of the left ventricle, and stored in digital format. Doppler pulsed wave measurements were obtained at the aortic annulus (AoAnn) level in the apical "5-chamber" view to assess the velocity time integral (VTI) over the aortic valve. 
Assessment of left ventricular dimensions included both LVedd and LVesd, and these were obtained by M-mode measurements. Shortening fraction was calculated from LVedd and LVesd using the formula ((LVedd - LVesd)/LVedd) (26). LVO was calculated using the formula $\left(\left(\left(\pi \times A_{o} A n^{2}\right) / 4\right) \times\right.$ VTI $\times$ HR $) /$ birth weight $(14)$. In this formula, $\left(\left(\left(\pi \times\right.\right.\right.$ AoAnn $\left.\left.\left.^{2}\right) / 4\right) \times \mathrm{VTI}\right)$ defines LVSV. The echocardiogram, echocardiographic measurements, and data analysis were performed by one observer (a senior consultant in pediatric cardiology). All infants received a comprehensive echocardiogram after the procedure to rule out any structural anomalies of the heart.

Data were analyzed using SPSS (version 20.0.0; IBM, Chicago, IL). Results are presented as mean (SD), mean (range), or median (IQR) where appropriate. Individual data of the three time points were compared using a paired-sample $t$-test. To account for multiple comparisons between the three time points, we performed the tests using the Bonferroni corrected level of $P=0.05 / 3=0.017$. The correlations between LVO, LVSV, and HR values were calculated using a Pearson's product-moment correlation. A value $<0.2$ was considered low, a value between 0.2 and 0.7 was considered moderate, and a value $>0.7$ was considered to reflect high correlation. A $P$ value of $<0.05$ was regarded as statistically significant. Reported $P$ values are two sided.

\section{ACKNOWLEDGMENTS}

We express our gratitude to the research nurses C. Kolster-Bijdevaate and M. $S$. Verhart for their help with the inclusion of our patients.

\section{STATEMENT OF FINANCIAL SUPPORT}

A.B.t.P. is recipient of a Veni-grant, The Netherlands Organisation for Health Research and Development (ZonMw), part of the Innovational Research Incentives Scheme Veni-Vidi-Vici, project number 91612027 . J.J.v.V. is recipient of a Willem-Alexander Children's Foundation scholarship.

Disclosure: None of the authors have a conflict of interest.

\section{REFERENCES}

1. te Pas AB, Davis PG, Hooper SB, Morley CJ. From liquid to air: breathing after birth. J Pediatr 2008;152:607-11.

2. Dawson JA, Kamlin CO, Wong C, et al. Changes in heart rate in the first minutes after birth. Arch Dis Child Fetal Neonatal Ed 2010;95:F177-81.

3. Hooper SB, Kitchen MJ, Siew ML, et al. Imaging lung aeration and lung liquid clearance at birth using phase contrast X-ray imaging. Clin Exp Pharmacol Physiol 2009;36:117-25.

4. Sobotka KS, Hooper SB, Allison BJ, et al. An initial sustained inflation improves the respiratory and cardiovascular transition at birth in preterm lambs. Pediatr Res 2011;70:56-60.

5. Gao Y, Raj JU. Regulation of the pulmonary circulation in the fetus and newborn. Physiol Rev 2010;90:1291-335.

6. Crossley KJ, Allison BJ, Polglase GR, Morley CJ, Davis PG, Hooper SB. Dynamic changes in the direction of blood flow through the ductus arteriosus at birth. J Physiol 2009;587(Pt 19):4695-704.

7. Heymann MA. Control of the pulmonary circulation in the fetus and during the transitional period to air breathing. Eur J Obstet Gynecol Reprod Biol 1999;84:127-32.
8. Teitel DF, Iwamoto HS, Rudolph AM. Effects of birth-related events on central blood flow patterns. Pediatr Res 1987;22:557-66.

9. Kattwinkel J, Perlman JM, Aziz K, et al.; American Heart Association. Neonatal resuscitation: 2010 American Heart Association Guidelines for Cardiopulmonary Resuscitation and Emergency Cardiovascular Care. Pediatrics 2010;126:e1400-13.

10. Noori S, Wlodaver A, Gottipati V, McCoy M, Schultz D, Escobedo M. Transitional changes in cardiac and cerebral hemodynamics in term neonates at birth. J Pediatr 2012;160:943-8.

11. Kent AL, Kecskes Z, Shadbolt B, Falk MC. Normative blood pressure data in the early neonatal period. Pediatr Nephrol 2007;22:1335-41.

12. Jones JE, Jose PA. Neonatal blood pressure regulation. Semin Perinatol 2004;28:141-8.

13. Lind, J. Disturbances in the Postnatal Closure of the Various Blood Vessels and Channels and Their Relation to Asphyxia. Symposium on Anoxia of the Newborn Infant. The Council for International Organizations of Medical Sciences. Oxford: Blackwell Scientific Publications, 1953.

14. Mielke G, Benda N. Cardiac output and central distribution of blood flow in the human fetus. Circulation 2001;103:1662-8.

15. Stopfkuchen $\mathrm{H}$. Changes of the cardiovascular system during the perinatal period. Eur J Pediatr 1987;146:545-9.

16. Winberg P, Jansson M, Marions L, Lundell BP. Left ventricular output during postnatal circulatory adaptation in healthy infants born at full term. Arch Dis Child 1989;64(10 Spec No):1374-8.

17. Agata $Y$, Hiraishi $S$, Oguchi K, et al. Changes in left ventricular output from fetal to early neonatal life. J Pediatr 1991;119:441-5.

18. Sharma A, Ford S, Calvert J. Adaptation for life: a review of neonatal physiology. Anaesth Intensive Care Med 2010;12:85-90.

19. Grant DA, Kondo CS, Maloney JE, Walker AM, Tyberg JV. Changes in pericardial pressure during the perinatal period. Circulation 1992;86:1615-21.

20. Rabe H, Diaz-Rossello JL, Duley L, Dowswell T. Effect of timing of umbilical cord clamping and other strategies to influence placental transfusion at preterm birth on maternal and infant outcomes. Cochrane Database Syst Rev 2012;8:CD003248.

21. Sommers R, Stonestreet BS, Oh W, et al. Hemodynamic effects of delayed cord clamping in premature infants. Pediatrics 2012;129:e667-72.

22. Hudson I, Houston A, Aitchison T, Holland B, Turner T. Reproducibility of measurements of cardiac output in newborn infants by Doppler ultrasound. Arch Dis Child 1990;65(1 Spec No):15-9.

23. Tsai-Goodman B, Martin RP, Marlow N, Skinner JR. The repeatability of echocardiographic determination of right ventricular output in the newborn. Cardiol Young 2001;11:188-94.

24. Murase M, Ishida A, Momota T. Serial pulsed Doppler assessment of early left ventricular output in critically ill very low-birth-weight infants. Pediatr Cardiol 2002;23:442-8.

25. Kamlin CO, Dawson JA, O’Donnell CP, et al. Accuracy of pulse oximetry measurement of heart rate of newborn infants in the delivery room. J Pediatr 2008;152:756-60.

26. Rein AJ, Sanders SP, Colan SD, Parness IA, Epstein M. Left ventricular mechanics in the normal newborn. Circulation 1987;76:1029-36. 